already possible to rule out various of the published models of 5S RNA, for example, with some conviction. Tinoco et al. demonstrate what has been so mulishly ignored in the past, that base-pairing can actually destabilize a structure, if it is bought at the cost of too many entropically unfavourable loops and bulges.

There is every promise that this rational approach will prosper. Meanwhile, in a world apart, X-ray crystallographers are pursuing structures, at least of tRNAs, directly. Kim et al. (Proc. US Nat. Acad. Sci., 68, 841; 1971) have reached the point of showing, by virtue of the low symmetry of short segments of base-pairs, which allows the helix spacings to be apparent when viewed from one angle but not from another, that yeast phenylalanine tRNA contains short duplexes, of no more than some $4-7$ base-pairs, more or less as expected from the cloverleaf model.

\section{FRESHWATER BIOLOGY}

\section{Thermal Efiects}

from a Correspondent

REPRESENTATIVES from a wide range of institutions attended a symposium on freshwater biology and electrical power generation at the Central Electricity Research Laboratories (CERL), Leatherhead, on April 22. The principal object of this symposium was to present recent CERL work in this field to a wider audience and to give other biologists the opportunity to discuss it.

The first speakers considered the discharge of warmed water from power stations into rivers. In his discussion on the effects of heating polluted water, Mr J. S. Alabaster (Water Pollution Research Laboratory) said that on parts of the River Trent where cooling towers are used, the net effect on water quality and on the status of the fishery seems to be beneficial; water gains oxygen and loses ammonia on passage through the towers. Mr T. E. Langford (CERL) has been unable to show any apparent correlation between the general composition of river faunas and maximum temperature, at least up to $32^{\circ} \mathrm{C}$, after sampling around twenty power stations on twelve rivers.

Several speakers expressed the view that biologists did not often provide information in a form which could be readily used by management. For example, there had been some reluctance to classify rivers on some biologically comparative basis. A need for more biological monitoring of rivers was emphasized, and other speakers felt that existing information needed to be collated and codified at once.

Dr J. E. Rippon (CERL) discussed microbiological problems associated with different aquatic environments in and around power stations, including the bacteria of demineralized water in cable cooling circuits, condensate associated with turbine lubricating oils and condenser slimes. Some influences of power station discharge on man-made Lake Trawsfynydd in North Wales were outlined. $\mathrm{Mr}$ J. W. Whitehouse and Mrs S. Luff (CERL) on plankton showed that, whereas the phytoplankton are evenly distributed throughout the lake and had shown no changes which might be attributed to warming, the zooplankton exists as two discrete populations, one in the warm lagoon, the other in the larger, cool lake. The two populations of Cyclops abyssorum do not differ significantly in size or fecundity. Benthic surveys by $\mathrm{Dr} D$. R. Rothwell (Liverpool Polytechnic) have revealed a lack of fauna in the warm lagoon, but this lack is probably not the result of the raised temperature; the possibility that chelation of trace metals on peat and erosion is involved is, however, being considered.

A good example of an experimental study being used to aid interpretation of field results was provided by Dr R. J. Aston (CERL), who dealt with the effects of temperature and oxygen concentration on two tubificid worms. $\mathrm{Mr}$ A. Aitken (University of Nottingham) showed how lipid can be utilized in place of protein when rainbow trout are maintained at elevated temperatures. The importance of considering fluctuating temperatures as well as constant conditions in experimental studies was stressed by $\mathrm{Mr}$ B. G. Lewis (CERL), who showed how, in Cyclops abyssorum, variations in temperature can affect the rate of development differently.

Two aspects of work described by $\mathrm{Dr}$ K. U. Clarke (University of Nottingham) on the effect of temperature and photoperiod on the endocrine system and chromosome puffing in Chironomus sp. are of particular relevance to the identification of thermal effects: tem-

\title{
Morphology of Polyethylene
}

PRUD'HOMME and Stein report in next Monday's Nature Physical Science that they have obtained conclusive evidence of the microspherulitic structure of polyethylene using a novel extension of the techniques of low angle light scattering to polymer films.

Light scattering photographs were taken of films 25 to $725 \mu \mathrm{m}$ thick using $\mathrm{H}_{\mathrm{v}}$ polarization with a laser source, and they exhibited a pattern characteristic of scattering from anisotropic spheres. The diameters of the scattering entities were in good agreement with those obtained for spherulites by Booth and Hay (Nature, 227, $701 ; 1970$ ) in thin films of low density 'Rigidex' polyethylene; the lower diameters observed in high density fractions and resolvable only with a stereoscan electron microscope suggest that variations in sample characteristics and crystallization procedures can be effective in changing the nucleation density. Nevertheless, it now seems well established that the lack of resolution of the spherulites by light microscopy is caused by sample thickness and in particular clouding of the contours of the spherulites by the large percentage of birefringent units present.

There is, however, no evidence as yet that polyethylene is capable of producing larger spherulites with diameters 0.1 to $1.0 \mathrm{~mm}$ except after excessive heat treatment. Accordingly, the conclusions of Banks et al. (Nature, 194, $542 ; 1962)$ that these structures are not representative of polyethylene samples as a whole-because they are most probably artefacts of the heat treat- ment (degradation or strain produced on thinning the samples)-must still be considered valid.

Spherulites are the form in which one expects high molecular weight substances to crystallize from the melt, and the only unusual characteristic of polyethylene spherulites seems to be their small size. There is clearly a high nucleation density which would also account for the extreme difficulty in obtaining polyethylene in a quenched amorphous state.

Spherulites of polymeric materials are formed from radiating arrays of fibre-like crystals which have developed from single crystal nuclei by a process of preferential growth along one crystallographic axis and repeated branching. They thus accumulate into sheaves and finally into spheres.

The final stage of spherical growth is amenable to kinetic analysis in terms of the general crystallization rate equation, $1-X_{t}=\exp \left(-Z t^{n}\right)$, which relates the crystallinity to time and in which $n$ is 3 or 4. Analysis of the crystallization isotherms of polyethylene by means of this expression has not been particularly successful because it yields anomalous fractional $n$ values. Because the final morphology of bulk crystallized polyethylene is microspherulitic, the assumption that spherical growth predominates during most of the crystallization process cannot be justified. Further detailed analysis of the fine structure of polyethylene spherulites during their development is clearly required in order to determine a more appropriate rate expression. 